\title{
Prevalence of disordered eating attitudes among adolescent girls in Arar City, Kingdom of Saudi Arabia
}

\author{
Waseem Fatima, Leena M. Ahmad \\ Faculty of Medical and Applied Medical Sciences, Northern Boarder University, Arar, \\ Kingdom of Saudi Arabia
}

\begin{abstract}
Eating disorders (ED) are one of the most common psychiatric problems faced by todays adolescent girls where the attitude towards weight and shape as well as their perception of body shape are disturbed. The aim of the paper is to assess the prevalence and associated factors of disordered eating attitudes among adolescent girls of Arar city, Kingdom of Saudi Arabia. This is a cross-sectional survey design in which 314 adolescents females (age: 15-19 years) were selected from four schools of Arar city, KSA. Subjects were asked to fill pre-tested questionnaire about socioeconomic status, eating habits and Eating attitude test 26 (EAT 26), there height and weight were measured and BMI was calculated. Disturbed eating behaviors (EAT-26>20) was found in $25.47 \%$ participants. The prevalence of disordered eating was more in overweight and obese than normal weight. Vegetarian girls had higher EAT 26 score than non - vegetarian and significant difference was found in total EAT 26 score and subgroup namely oral control and dieting score $(\mathrm{P}<0.01)$ but non-significant
\end{abstract}

Correspondence: Waseem Fatima, Department of Clinical Nutrition, Faculty of Medical and Applied Medical Sciences, Northern Boarder University, Arar, Kingdom of Saudi Arabia.

Tel.: 966501286515

E-mail: fatimawaseem1512@gmail.com

Key words: Adolescent girls; Eating Attitude Eating Disorder; KSA, Weight status.

Acknowledgments: the authors gratefully acknowledge the approval and the support of this research study by the grant no. AMS-2017-1-7F-6959 from the Deanship of Scientific Research at Northern Border University, Arar, K.S.A

Contributions: the authors contributed equally.

Conflicts of interest: the authors declare no potential conflict of interest

Funding: Deanship of Scientific Research, Northern Border University, Arar, K.S.A.

Received for publication: 19 April 2018.

Revision received: 17 September 2018.

Accepted for publication: 5 October 2018.

This work is licensed under a Creative Commons AttributionNonCommercial 4.0 International License (CC BY-NC 4.0).

(C) Copyright W. Fatima and L.M. Ahmad, 2018

Licensee PAGEPress, Italy

Health Psychology Research 2018; 6:7444 difference was found between Saudi and non-Saudi adolescent girls in different BMI ranges. Eating disorders prevalent in adolescent girls and were strongly associated with weight status and eating habits. Future prospective and experimental studies are warranted to advance our understanding of the risk factors to enable better preventive program planning.

\section{Introduction}

Adolescence is a unique and distinct developmental period, which comprises both psychological and physiological processes of change (Kadriu, Kelpi, \& Kalyva, 2014). It is considered as a nutritionally vulnerable stage of life because they are prone to a number of health problems which are attributed to their lifestyle and eating habits. Several studies have shown high prevalence of overweight and obesity in adolescents girls (Musaiger et al., 2016) which coupled with rapid socio-cultural changes puts them at risk for developing various eating disorders such as Anorexia nervosa, Bulimia nervosa, frequent dieting, binge eating and partial syndromes (Latzer, Azaiza, \& Tzischinsky, 2014; Mousa, Al-Domi, Mashal, \& Jibril, 2010).

Eating disorders characterized by chronicity and relapse along with disordered eating behavior where the adolescent girls' attitude towards weight and shape, as well as their perception of body shape, are disturbed. It is a complex illness that has impact on both physical and socio-emotional health of adolescents, and contributes to significant morbidity. Eating disorders are one of the most common psychiatric problems, have the highest mortality rates of all mental disorders(Quick, Byrd-Bredbenner, \& Neumark-Sztainer, 2013).

Although eating disorders were originally believed to occur mainly in affluent Western countries (Abdollahi \& Mann, 2001; Chang et al., 2015; Nasser, 1986). However, epidemiological data indicate eating disorders increasing dramatically worldwide in past two decades and occur across all ethnic, cultural, and socioeconomic groups and the most vulnerable group for anorexia nervosa comprised girls and young women aged 15 to 24 years (Cummins, Simmons, \& Zane, 2005; Grigg, Bowman, \& Redman, 1996; Szabo \& Hollands, 1997)

Many theorists believe that that high prevalence of disordered eating is due to the Westernization because it emphases on thinness and propagating slenderness (Nasser, 1986; Rauof, Ebrahimi, Asghari Jafarabadi, Malek, \& Babapour Kheiroddin, 2015). In last few decades rapid cross-cultural social changes occurred in many Arabian countries, the attitudes and behaviors of the new generation have borrowed western values (Amir, 2015, ; Bas, Asci, Karabudak, \& Kiziltan, 2004; Fath Al Alim M Abdelrahim, , \& Abdelghani Alshaikh 2012; Latzer et al., 2014). Nonetheless, customary Arab populations have been found to place value on plumpness; a sign of beauty, fertility and good health.(Abdollahi 
\& Mann, 2001) Consequently, adolescent's girls, experiencing a growing conflict between Western values and Arabic traditions and this cultural clash between a traditional culture and adopted Westernized culture heightened the risk for eating disorders in them. (Latzer et al., 2014) Recently, high prevalence of abnormal Eating attitude and behaviors is confirmed by nonclinical studies in several Arab countries (Fath Al Alim M Abdelrahim et al., 2012; Haleama Al Sabbah, 2016; Kazim AA, 2017; Rafia Bano, 2013). Considering the fact that disordered eating attitude can be turned into eating disorder and its consequences are quite severe, Therefore, Early identification is essential to reduce complications of eating disorders that occur during these stages of growth and development.(D'Souza, Forman, \& Austin, 2005)

Despite of high prevalence of disorder eating attitude there is limited numbers of studies that have been conducted in Arab countries, particularly Saudi Arabia. Therefore, keeping in view the seriousness of problem on one hand and lack of knowledge of eating attitude on the other, the present study carried out in Arar city, KSA with following aim and objectives. 1. To determine the Prevalence of abnormal Eating attitude among adolescents girls. 2 . To find out association of weight status, eating habits and age at menarche with eating attitudes among study population. 3 . To find out associations between a range of socio-environmental factors and eating disorder among a sample of adolescent females.

\section{Materials and Methods}

Research Design: Cross-sectional Survey design was used to conduct this study.

Study site: For the purpose of study, Arar city of Kingdom Saudi Arabia was selected. Arar is

located to the north-east of Saudi Arabia on the Iraqi border.

Study Population: Adolescents girls age range between 15-19 years were selected.

Research setting: Four schools were selected by stratified random sampling method by dividing city into specific zones, to ensure that the study was representative of the whole city. After identifying schools from each zone, school authorities were approached personally with the recommendation letter from deanship of research, Northern Border University, Arar and the purpose and nature of study was explained to them. Based on the consent and active cooperation of the school authorities: one school from each region were selected. Timetable of all the classes, sectionwise, were obtain from the authority for easy approachability and to avoid any academic interruption.

Pilot study: Initial versions of the questionnaire and all the techniques for measurement anthropometrical examination were piloted on a set of 30 adolescent girls in Afaf international school for the purpose of getting the prevalence disordered eating and to test the efficiency of the questionnaire. Consequently, the content of the questionnaire was modified and minor changes were made in the method of gathering information about various variables of the study.

Sample Size: The study sample size of was calculated using the Cochran's Formula

$n_{0}=\frac{Z^{2} p q}{e^{2}}$

where, e is the desired level of precision (i.e. the margin of error), $\mathrm{p}$ is the (estimated) proportion of the population, $\mathrm{q}$ is $1-\mathrm{p}$.
Considering, 30\% prevalence disordered eating among adolescent (pilot study) in Arar, with 95\% confidence level, the sample size was calculated to be $\left.322\left[(1.96)^{2}(0.3)(0.7)\right) /(0.05)^{2}=322\right]$. But, 8 subjects did not give concern, therefore sample of 314 adolescents were interviewed, with response rate of $97.51 \%$.

Sampling Technique: Stratified Random Sampling Technique was used for data collection.

Data Collection Period: 4 months, from October 2017 to January, 2018.

Exclusion criteria: Students who have chronic diseases, obesity other than exogenous dietetic

and those who are pregnant will be excluded from the study.

Inclusion Criteria: Females students (15 to 19 years of age).

Data Collection Process: The researchers introduce themselves and briefly explain the study

objectives to participants. Then, the participants asked to proceed to fill in the questionnaires under

the supervision of the researchers.

Tools of data collection. Two types data collection tools were used in present study: 1. Questionnaire, 2. Anthropometric measurements (height and weight).

\section{Questionnaire}

Questionnaire was translated in Arabic language and two Arabic professor double check it to understand eating behaviors that consequently could affect their nutritional

Status. Questionnaire divided into two sections:

Section (A) in which socio-demographic characteristics such as education level, nationality , their family size, household type, parent's educational and employment status, pubertal status, health status and information about eating habits were collected.

Section (B) The Eating Attitudes Test (EAT-26) was used to measure disordered eating attitudes and it consists of 26 statements referring to various eating attitudes and behavior. Each statement uses a six-point Likert-type scale ranging from 'always' to 'never'. A score of 3 points was given for 'always', 2 for 'usually', 1 for 'often', and 0 for 'sometimes', 'rarely' and 'never'. Only item number $26^{\text {th }}$ item evaluated in a opposite way i.e. 0 points was given for 'always', 'usually', and 'often', and 1, 2, and 3 for 'sometimes', 'rarely' and 'never' respectively. The responses of all the 26 items were summed at the end and the respondents, who score exactly at, or above, the cut off score of 20 , considered at risk of disordered eating attitudes and behaviors. The three factors of EAT-26 were classified according to Garner et al. (Garner, Olmstead, \& Polivy, 1983) are dieting, bulimia and food preoccupation and oral control. Dieting, which reflects restricting intake of high caloric foods and preoccupation with body image/shape and his factor consisted of 13 items; bulimia and food preoccupation describes thoughts regarding food, binging and self-induced vomiting. This dimension included 6 items such as "have gone on eating binges where I feel I may not be able to stop", as well as "feel that food controls my life" etc; and oral control include 7 items that illustrates the ability to regulate food intake and perceived pressure from others to gain weight.

\section{Validity of the study's questionnaire}

EAT 26 has high internal consistency $(\alpha=0.90)$ and acceptable criterion-related validity, being highly accurate in classifying eating disordered and non-eating disordered individuals. EAT-26 was also validated by Al-Subaie et al. in Saudi Arabia. (Al-Subaie et al., 1996). 


\section{Anthropometric measurements}

The weight of student was recorded with the help of platform spring balance zero error checked and remove it if present every day prior to start data collection. The students remain in school uniform without heavy woolen cloth and shoes. The weight measures up to accurately of 500 gram and nearest reading was recorded. The same weighing machine was used in whole study.

Height measured in centimeters by using standard stediometer. The student asked to stand erect without shoes with the support to the wall with erect head eyes straight and head, buttocks, heels, shoulder and back touching with the stediometer scale. The height recorded up to nearest $1 \mathrm{~cm}$ when the metallic scale brought down on the head, pressing the hair and touching the head. BMI was calculated as weight $/$ height $^{2}$, with weight being in kilograms and height being in meters.

\section{Data analyses}

SPSS 22 (2017) Statistics for Windows was used in entering, managing survey data and in generating the statistics. Mean, SD, percentages, independent t-test, ANOVA and chi square was applied at the 0.05 level of significance.

\section{Results}

In the present study, 314 students included for data analysis purpose. According to diagnostic criteria of EAT-26, 80 students
$(25.4 \%)$ were at risk of eating disorder (Table 1). The mean age of all students was $17.07(\mathrm{SD}=1.14)$ with the minimum age of 15 and maximum of 19 years.

Majority of them, 249 (79.29\%) live in large family (Family Size $>7)$ and $244(77.70 \%)$ third or more than third born child of their parents. Most of them $(97.13 \%)$ attain menarche between eleven to thirteen years of age. Among the study population, 156 $(49.68 \%)$ have normal weight and were at not risk of developing eating disorder. Although, significant difference found in prevalence of disordered eating attitudes in different BMI ranges $(\mathrm{P}<0.001)$. Only $21(6.68 \%)$ participants were vegetarians, and 293 $(93.31 \%)$ were non-vegetarians and significant association was found between eating habits and disordered eating attitudes among study population $(\mathrm{P}<0.001)$.

Figure 1 illustrated the risk of ED with the EAT-26 criteria regarding age and found that girls at the age of 17 to 18 are at great risk of developing eating disorder but difference was not statistically significant. Table 2 depicted correlation of total EAT 26 score, eat 26 sub-scales (namely oral, bulimia and dieting) and their anthropometric measurements. Significant negative correlation was found between weight and BMI with eat 26 total score whereas positive correlation was found between dieting subgroup with age, weight and BMI ( $\mathrm{P}>.01)$ whereas oral control sub group was correlated with age only $(\mathrm{P}<.05)$.

Table 3 shows mean and SD of EAT-26 score in different subgroups according to their eating habits and higher score was found in vegetarian than non-vegetarian in all subgroups. Score in eat 26 (total) dieting behavior, oral control and bulimia subgroup was $20.67 \pm 13.21,10.21 \pm 7.65,4.42 \pm 2.90,3.66 \pm 4.14$ respectively in

Table 1. Association between female schoolgirls' characteristics and disordered eating attitudes.

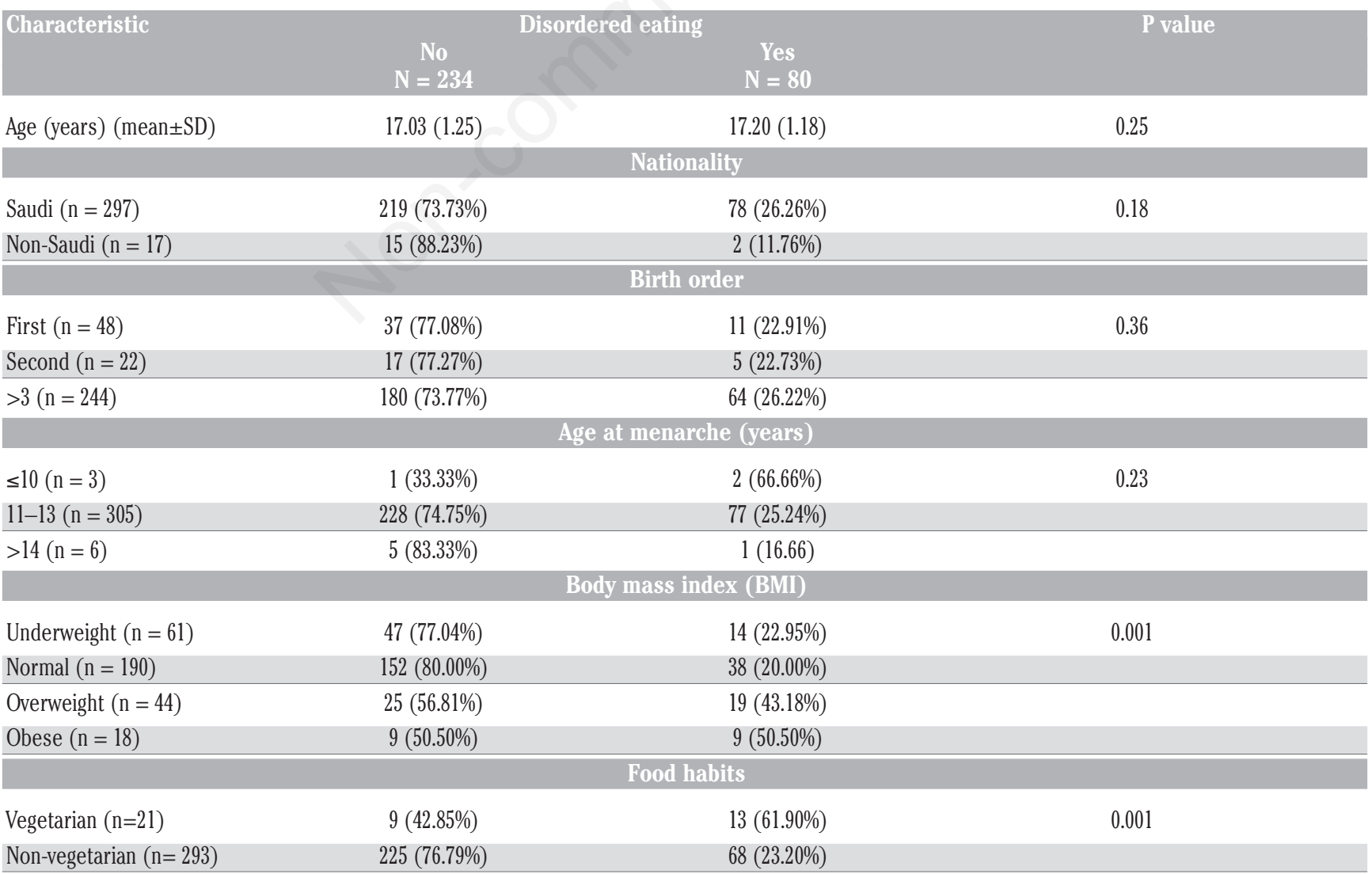


vegetarian and $13.21 \pm 9.07,6.03 \pm 5.15,3.75 \pm 3.16, \quad 2.27 \pm 2.44$ respectively among non-vegetarian and highly significantly different was found between eating habits with EAT 26 subgroups except in bulimia subgroup.

On comparing the prevalence of eating disorder among Saudi and Non-Saudi population according to weight status it was found among Saudi adolescent's girls, 26.26\% (78/297) showed a disorder eating behavior in the EAT 26 and in the group of foreign teenagers, $11.76 \%(2 / 17)$ girls showed disordered eating patterns. The results suggest that the Saudi girls are 2.23 times more likely to develop anorexic-like behavior than the non-Saudi girls. The chi-square independence test (Pearson chi-square) was used to determine whether risk behaviors for eating disorders differed by adolescents' nationality but non-significant difference was found in weight status among the Saudi and non- Saudi students with normal eating attitude and disordered eating attitude (Table 4).

\section{Discussion}

Disordered eating attitudes are epidemic worldwide, and the adolescent girls are at high risk for disordered eating attitudes. The results of present study also indicate that adolescents girls suffer from higher rates of eating disordered attitudes and behaviors similar to levels reported in other national and international literature, which suggests that the prevalence of unhealthy weight control practices, such as dieting, fasting, purging (i.e. vomiting, laxatives and diuretics' use, diet pills), binge eating, have increased exponentially in the past two decades (Amir, 2015, ; Chang et al., 2015; Rauof et al., 2015; Thomas J, 2010). The present study suggests the overall prevalence of abnormal eating attitudes and behavior among to be $25.47 \%$ as elicited by the EAT 26 .

The prevalence of disorder eating attitudes in western countries varies from $0.4 \%$ in Spain (Ballester Ferrando, De Gracia Blanco, Patino Maso, Sunol Gurnes, \& Ferrer Avelli, 2002) to 33.\% in Australia (Grigg et al., 1996). Szabo and Hollands (Szabo $\&$ Hollands, 1997) found $37.5 \%$ of the black female high school students had abnormal eating attitudes in south Africa. Whereas, the prevalence of disordered eating attitudes and behaviors was $21.7 \%$ in Pakistan,(Babar et al., 2002) and $14.76 \%$ in India (Srinivasan, Suresh, Jayaram, \& Fernandez, 1995).

Although epidemiological studies regarding risk behaviors for eating disorders are scarce in Arabic countries. Recently, high prevalence of abnormal Eating attitude and behaviors is confirmed by nonclinical studies (scored $>20$, Eating Attitude Test (EAT 26) cutoff score for clinical significance) in several countries like United Arab Emirates (UAE), Jorden, and Sudan was 36.7\%, 33\%, and $21 \%$ respectively (Fath Al Alim M Abdelrahim et al., 2012; Kazim AA, 2017; Mousa et al., 2010). Other study form UAE reveled $23.4 \%$ and $66 \%$ of adolescent girls in the were engaged in negative eating attitudes and desired to be thin, respectively, was associated with age, BMI and watching western TV programs (Eapen, Mabrouk, \& Bin-Othman, 2006) . Studies representing Saudi students from different cities like Hail, Jeddah, and Riyadh found scored of 20 and above using Eating Attitude Test (EAT-26) was $36 \%, 32.9 \%$ and $24.6 \%$ respectively. (Al-Subaie, 1998; Fallatah1, 2015; Rafia Bano, 2013).

Musaiger et al., (Musaiger et al., 2016) highlighted the magnitude of the risk of disordered eating attitudes among adolescents in seven Arab countries and found, risk of disordered eating attitude was twice as high among females as in males and risk of disordered eating attitude among obese adolescents was two to three times higher than that of non-obese, in both genders.

Result of present study also shows that female students overweight and obese students endorsed more risk factors for disordered eating than those with normal BMI scores. This finding was consistent with previous literature in different Arab countries,

Table 2. Correlation of girls' total EAT 26 score, eat 26 sub-scales and their anthropometric measurements.

\begin{tabular}{lcccc} 
& Age & Weight & Height & BMI \\
EAT 26 & -0.07 & $-0.20^{* *}$ & -0.09 & $-0.19^{* *}$ \\
ORAL & $0.11^{*}$ & 0.04 & 0.01 & 0.01 \\
\hline DIETING & $0.01^{* *}$ & $0.27^{* *}$ & 0.09 & $0.26^{* *}$ \\
BLUMINIA & 0.01 & 0.08 & 0.09 & 0.05 \\
\hline
\end{tabular}

${ }^{*}$ Correlation is significant at 0.05 level. ${ }^{* *}$ Correlation is significant at 0.01 level

Table 3. Mean and SD of EAT 26 subgroup score of participants according their eating habits.

\begin{tabular}{lccc} 
EAT 26 score & Vegetarian & Non-vegetarian & P value \\
EAT 26 (total) & $20.67 \pm 13.21$ & $13.21 \pm 9.07$ & .00 \\
Dieting & $10.21 \pm 7.65$ & $6.03 \pm 5.15$ & .00 \\
\hline Oral & $4.42 \pm 2.90$ & $3.75 \pm 3.16$ & .01 \\
Bulimia & $3.66 \pm 4.14$ & $2.27 \pm 2.44$ & .36 \\
\hline
\end{tabular}

Table 4. Association of weight status in normal and distorted eating attitude groups among study population adolescents with nationality.

\begin{tabular}{|c|c|c|c|c|}
\hline EAT 26 & Weight & Nat & lity & P-value \\
\hline & status & Saudi & Non-Saudi & \\
\hline$>20$ & Underweight & $14(17.50 \%)$ & $0(00 \%)$ & 0.51 \\
\hline & Normal & $36(45.00 \%)$ & $2(2.50 \%)$ & \\
\hline & Overweight & $19(23.75 \%)$ & $0(00 \%)$ & \\
\hline & Obese & $9(11.25 \%)$ & $0(00 \%)$ & \\
\hline$<20$ & Underweight & 46 (19.65\%) & $1(00.42 \%)$ & 0.56 \\
\hline & Normal & $141(60.25 \%)$ & $11(4.70 \%)$ & \\
\hline & Overweight & $23(9.82 \%)$ & $2(00.85 \%)$ & \\
\hline & Obese & $8(3.410 \%)$ & $1(00.42 \%)$ & \\
\hline
\end{tabular}

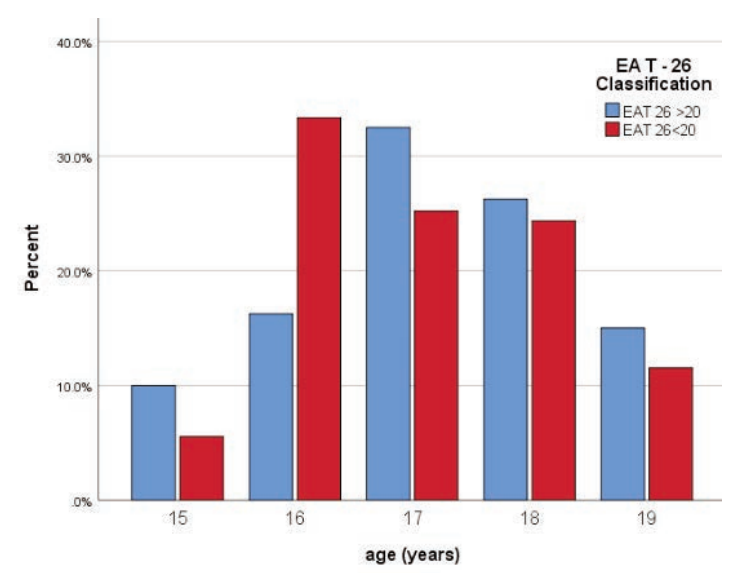

Figure 1. Risk of eating disorder with the EAT-26 criteria regarding age. 
which found a significant relation between abnormal BMI and higher EAT scores. (Al-Subaie et al., 1996) and found no significant association between any of studied students' baseline characteristics (age, family size, birth order and age of menarche) and disordered eating attitudes (Allihaibi, 2015).

Our finding that vegetarianism was related with abnormal eating behavior among female students consistent with the claimed hypothesis that vegetarianism emerged as the most potent predictor of eating pathology. Similar result was found in a Minnesota study, vegetarian were twice likely to be dieter and four time to used vomit for weight control vegetarian (NeumarkSztainer \& Story, 1998). 65\% Anorexia nervosa patients in western countries state to be vegetarians (Aloufy \& Latzer, 2006).

Many researches show that a growing number of people, especially young women are adopting vegetarianism and eliminates meat and/or animal products from diet and follow restrictive eating patterns. Beside health, moral and ethical belief, the main reasons for adopting vegetarian and vegan diets were to lose weight, maintain low body weight. The information on the role vegetarianism plays in eating disorder is certainly mixed and complex. On the other hand many studies reported Vegetarianism as a method for complicating the normalization of eating rather than a simple risk factor for eating disorders and avoidance of meat does not precede the onset of the eating disorder symptoms (Aloufy \& Latzer, 2006)

The present study allows sampling across several national and cultural backgrounds within the country. It is interesting to speculate on the factors that could account for the rising tide of disordered eating among adolescents' girls. First, is it possible that the rapid population growth in particular age groups that are vulnerable to adjustment difficulties is contributing to the disordered eating. Second, although kingdom of Saudi Arabia, appear rising tide of acculturation and westernization that may lead to cultural clash. In finding of present study that Saudi adolescents girls at risk of developing eating disorder this might be because Saudi females are of higher socioeconomic status and are more influenced by westernization than non-Saudis females (Latzer et al., 2014).

\section{Limitations}

The study was a cross-sectional and had nonprobability nature of the sampling. It was only one stage study and no clinical interview were performed to diagnose eating disorders. Only EAT-26 was used as a screening instrument and the use of a questionnaire alone is not sufficient to make an eating disorder diagnosis (D’Souza et al., 2005; Garfinkel \& Newman, 2001). Another limitation was our study relatively small sample and only female students included in study.

\section{Conclusions}

This study was the first to examine the prevalence of disturbed eating attitudes in Arar city of kingdom of Saudi Arabia and suggest that the high prevalence of disordered eating attitude among female adolescents. Therefore, finding of present study will provide base line data regarding eating disorder for other researchers and to identify and target these adolescents for intervention more epidemiological studies could be conducted by the qualified professional. An alarming increase in the prevalence of eating disordered among adolescents were reported in the country like Saudi Arabia thus scientifically based guideline should be developed for the initial evaluation, diagnosis, and treatment of eating disorders. An interdisciplinary team approach for the diagnosing and treat- ment of eating disorders should include physician, a psychotherapist, a dietitian or clinical nutritionist and eating disorder specialist.

Furthermore, the results can be used to plan health awareness campaigns to prevent eating disorder among the Saudi youth. School authorities and government should develop educational program targeting eating behaviors of adolescents, highlight the importance of healthy eating pattern and consequences of eating disorder.

\section{References}

Abdollahi, P., \& Mann, T. (2001). Eating disorder symptoms and body image concerns in Iran: comparisons between Iranian women in Iran and in America. Int J Eat Disord, 30(3), 259268.

Al-Subaie, A. (1998). Eating Attitute Teast In Arabic: Psycometric Features And Normetic Data Saudi medical journal, 19(6).

Al-Subaie, A., Al-Shammari, S., Bamgboye, E., Al-Sabhan, K., AlShehri, S., \& Bannah, A. R. (1996). Validity of the Arabic version of the eating attitude test. International Journal of Eating Disorders, 20(3), 321-324. doi:10.1002/(SICI)1098108X(199611)20:3<321::AID-EAT12>3.0.CO;2-2

Allihaibi, M. M. (2015). Disordered eating attitudes among secondary schoolgirls in Al-Iskan sector, Makkah AlMukarramah,

Saudi Arabia. International Journal Of Medical Science And Public Health, 4(7).

Aloufy, A., \& Latzer, Y. (2006). [Diet or health-the linkage between vegetarianism and anorexia nervosa]. Harefuah, 145(7), 526-531, 549.

Amir, S. J.-F. S. C. a. T. M. N. (2015, ). Disordered Eating and its Association with Overweight and Health-Related Quality of Life Among Adolescents in Selected High Schools of Tehran. Child Psychiatry \& Human Development, 46(3).

Babar, N., Alam, M., Ali, S. S., Ansari, A., Atiq, M., Awais, A., . . Israr, S. M. (2002). Anorexic behaviour and attitudes among female medical and nursing students at a private university hospital. J Pak Med Assoc, 52(6), 272-276.

Ballester Ferrando, D., De Gracia Blanco, M., Patino Maso, J., Sunol Gurnes, C., \& Ferrer Avelli, M. (2002). [Eating attitudes and body satisfaction in adolescents: a prevalence study]. Actas Esp Psiquiatr, 30(4), 207-212.

Bas, M., Asci, F. H., Karabudak, E., \& Kiziltan, G. (2004). Eating attitudes and their psychological correlates among Turkish adolescents. Adolescence, 39(155), 593-599.

Chang, W.-w., Nie, M., Kang, Y.-w., He, L.-p., Jin, Y.-1., \& Yao, Y.s. (2015). Subclinical eating disorders in female medical students in Anhui, China: a cross-sectional study. Nutrición Hospitalaria, 31(4), 1771-1777.

Cummins, L. H., Simmons, A. M., \& Zane, N. W. S. (2005). Eating Disorders in Asian Populations: A Critique of Current Approaches to the Study of Culture, Ethnicity, and Eating Disorders. American Journal of Orthopsychiatry, 75(4), 553574. doi:10.1037/0002-9432.75.4.553

D'Souza, C. M., Forman, S. F., \& Austin, S. B. (2005). Follow-up evaluation of a high school eating disorders screening program: knowledge, awareness and self-referral. J Adolesc Health, 36(3), 208-213. doi:10.1016/j.jadohealth.2004.01.014

Eapen, V., Mabrouk, A. A., \& Bin-Othman, S. (2006). Disordered eating attitudes and symptomatology among adolescent girls in 
the United Arab Emirates. Eat Behav, 7(1), 53-60. doi:10.1016/j.eatbeh.2005.07.001

Fallatah1, A., , M. A.-H., \& , H. A.-G. (2015). Eating Disorders among Female Adolescents in Jeddah SCIENTIFIC COOPERATIONS MEDICAL WORKSHOPS( 21-22 July).

Fath Al Alim M Abdelrahim, , N. H. A., ,, \& Abdelghani Alshaikh (2012). Eating disorders symptoms among a university students: an exploratory study Sudan Med J, 48(3).

Garfinkel, P. E., \& Newman, A. (2001). The eating attitudes test: twenty-five years later. Eat Weight Disord, 6(1), 1-24.

Garner, D. M., Olmstead, M. P., \& Polivy, J. (1983). Development and validation of a multidimensional eating disorder inventory for anorexia nervosa and bulimia. International Journal of Eating Disorders, 2(2), 15-34. doi:10.1002/1098108X(198321)2:2<15::AID-EAT2260020203>3.0.CO;2-6

Grigg, M., Bowman, J., \& Redman, S. (1996). Disordered eating and unhealthy weight reduction practices among adolescent females. Prev $\mathrm{Med}, \quad 25(6), \quad 748-756$. doi:10.1006/pmed.1996.0115

Haleama Al Sabbah, S. M. (2016). Disordered Eating Attitudes and Exercise Behavior among Female Emirati College Students in the United Arab Emirates: A Cross- Sectional Study. Arab Journal of Nutrition and Exercise, , 1(1).

Kadriu, F., Kelpi, M., \& Kalyva, E. (2014). Eating-disordered Behaviours in Kosovo School-based Population: Potential Risk Factors. Procedia - Social and Behavioral Sciences, 114(Supplement C), 382-387. doi:https://doi.org/10.1016/j.sbspro.2013.12.716

Kazim AA, A. M., Karavetian M ((2017). The Prevalence and Determents of Eating disorders among Emirati Female Students Aged 14-19 Years in Ajman, UAE. J Food Nutr Disor Vol: 6 Issue: 2, 6(2).

Latzer, Y., Azaiza, F., \& Tzischinsky, O. (2014). Not just a western girls' problem: eating attitudes among Israeli-Arab adolescent boys and girls. International Journal of Adolescence and Youth, 19(3), 382-394. doi:10.1080/02673843.2012.747973

Mousa, T. Y., Al-Domi, H. A., Mashal, R. H., \& Jibril, M. A.
(2010). Eating disturbances among adolescent schoolgirls in Jordan. Appetite, 54(1), 196-201. doi:10.1016/j.appet.2009.10.008

Musaiger, A. O., Al-Kandari, F. I., Al-Mannai, M., Al-Faraj, A. M., Bouriki, F. A., Shehab, F. S., . . . Al-Qalaf, W. B. (2016). Disordered Eating Attitudes Among University Students in Kuwait: The Role of Gender and Obesity. International Journal of Preventive Medicine, 7, 67. doi:10.4103/20087802.180413

Nasser, M. (1986). Comparative study of the prevalence of abnormal eating attitudes among Arab female students of both London and Cairo universities. Psychol Med, 16(3), 621-625.

Neumark-Sztainer, D., \& Story, M. (1998). Dieting and binge eating among adolescents: what do they really mean? J Am Diet Assoc, 98(4), 446-450. doi:10.1016/s0002-8223(98)00101-1

Quick, V. M., Byrd-Bredbenner, C., \& Neumark-Sztainer, D. (2013). Chronic illness and disordered eating: a discussion of the literature. $A d v$ Nutr, 4(3), 277-286. doi:10.3945/an.112.003608

Rafia Bano, D. E. A., S. Shahida Banu. (2013). A Study on the Prevalence And Severity of Eating Disorders among the Young Population of Hail City in Saudi Arabia

GLOBAL JOURNAL FOR RESEARCH ANALYSIS, 2(6).

Rauof, M., Ebrahimi, H., Asghari Jafarabadi, M., Malek, A., \& Babapour Kheiroddin, J. (2015). Prevalence of Eating Disorders Among Adolescents in the Northwest of Iran. Iranian Red Crescent Medical Journal, 17(10), e19331. doi:10.5812/ircmj.19331

Srinivasan, T. N., Suresh, T. R., Jayaram, V., \& Fernandez, M. P. (1995). EATING DISORDERS IN INDIA. Indian Journal of Psychiatry, 37(1), 26-30.

Szabo, C. P., \& Hollands, C. (1997). Factors influencing eating attitudes in secondary-school girls in South Africa-a preliminary study. S Afr Med J, 87(4 Suppl), 531-534.

Thomas J, K. S. e. a., abdul rehama AA (2010). eating attitude and body image concern among female university students in the united Arab emirates Appetite, 54. 